\title{
SIKAP KOMUNIKATIF "SI BANG KOIN DAYA" ( SIKAP KEBANGSAAN DENGAN KONSELING LINTAS BUDAYA) SEBAGAI UPAYA PENGUATAN PENDIDIKAN KARAKTER GENERASI UNGGUL
}

\author{
Eko Setyorini \\ SMP Negeri 1 Kota Madiun \\ Echa.ayoen@gmail.com
}

\begin{abstract}
Abstrak
Pendidikan karakter menjadi solusi masalah-masalah yang terjadi seperti kekerasan, disintegrasi bangsa yang berpangkal karena perbedaan latar belakang dalam dunia pendidikan. Dunia pendidikan diharapkan menjadi penggerak untuk membangun budi pekerti dalam kehidupan menumbuhkan sifat kebangsaan sebagai wahana pembentukan generasi unggul penguat persatuan bangsa. Peserta didik menjadi agen perajut sikap kebangsaan sebagai individu pengurai solusi dalam masalah perbedaan budaya. Bimbingan dan konseling, pendekatan lintas budaya sebagai pennguatan sikap kebangsaan dalam wujud kegiatan komunikatif. Dalam konseling lintas budaya terlibat adanya relasi antara konselor dan konseli, artinya baik konselor maupun klien adalah manusia dengan karakteristiknya,kepribadiannya maupun budaya yang dibawa masing-masing. Dengan demikian relasi konseling tidak adanya perbedaan karakteristik (pribadi, nilai, moral, budaya) antara dirinya dengan kliennya, serta menghargai keunikan kliennya. Konseling lintas budaya mangakomodasi adanya perbedaan budaya. Kesadaran bersama bahwa Manusia Indonesia yang terdiri dari beragam suku dan bangsa yang kesemuanya itu ditujukan untuk saling mengenal budaya, adat istiadat, cara beribadah sebagai modal sikap kebangsaan. Maka dari itu konseling dibutuhkan sebagai solusi atas permasalahan yang menghambat munculnya sikap kebangsaan.
\end{abstract}

Kata Kunci: sikap kebangsaan, konseling lintas budaya dan generasi unggul

\begin{abstract}
Character education is a solution to the problems that occur such as violence, disintegration of the nation that originated because of differences in background in the world of education. The world of education is expected to be a mover to develop character in life to grow the national character as a vehicle for the formation of a superior generation that strengthens national unity. Students become agents of knitting national attitudes as individuals who decompose solutions to the problem of cultural differences. Guidance and counseling, cross-cultural approach as strengthening national attitudes in the form of communicative activities. In cross-cultural counseling involved a relationship between counselor and counselee, meaning that both the counselor and client are humans with their characteristics, personality and culture that are brought respectively. Thus the counseling relationship does not have differences in characteristics (personal, values, morals, culture) between himself and his client, and respects the uniqueness of his client. Crosscultural counseling accommodates cultural differences. The shared awareness that Indonesian people consist of various tribes and nationalities all of which are intended to get to know each other's culture, customs, ways of worship as a capital for national attitudes. Therefore counseling is needed as a solution to the problems that hinder the emergence of a national attitude.
\end{abstract}

Keywords: national attitude, cross-cultural counseling and superior generation

\section{PENDAHULUAN}

\section{Latar Belakang Masalah}

Nilai keberagaman hal nyata ada pada peserta didik. Sesuai kodrat dimiliki manusia, bahwa diciptakan sebagai individu dan makhluk sosial. Pendidikan adalah persoalan fokus dan tujuanya mampu memberikan imbas nyata. Paling tidak ada tiga fungsi pendidikan, fungsi tersebut sangat erat hubungannya dengan bimbingan dan konseling.Yaitu fungsi pengembangan, membantu individu mengembangkan potensi diri sesuai dengan potensinya, fungsi peragaman (diferensiasi), membantu individu memilih arah perkembangan yang tepat sesuai dengan potensinya, dan fungsi integrasi, membawa keragaman perkembangan ke arah tujuan yang sama sesuai dengan hakikat manusia untuk menjadi pribadi yang utuh.

Dalam kehidupan sosial keanekaragaman dapat memunculkan masalah dan konflik bila tidak ada kesepahaman di antara setiap individu. Apabila tidak diselesaikan dengan sebaik-baiknya maka akan terjadi konflik yang tidak diinginkan. Sebagai makhluk sosial, manusia bagian masyarakat di sekitarnya. Bagian lingkungan terkecil yang mempengaruhi pola kehidupan manusia adalah keluarga. Setelah itu, individu tersebut mulai melakukan interaksi pada lingkungan yang lebih luas, yaitu lingkungan masyarakat sekitarnya. Hal ini 
sesuai dengan Sulistyarini (2014: 261) bahwa, seluruh tingkah laku manusia tidak akan lepas dari kehidupan masyarakat yang ada di sekelilingnya.

Sebagai individu, manusia diciptakan dengan ciri berbeda. Dengan demikian, manusia atau individu dapat dikenali oleh orang lain dengan mengenal ciri-ciri tertentu yang dimilikinya. Kita pahami bersama bahwa proses pelaksanan kegiatan pendidikan merupakan secara sadar merupakan perihal utama kehidupan manusia, dengan pendidikan manusia bisa bertingkah laku sesuai kaidah manusiawi untuk mampu berkolaborasi dengan segala perbedaan yang ada. Dalam konteks ke-Indonesiaan, di mana Indonesia memiliki keanekaragaman baik suku, etnis, budaya, bahasa bahkan agama, program bimbingan konseling hendaknya memahami, memperhatikan, dan mempertimbangan keragaman tersebut sehingga terhindar dari sikap diskriminatif dan pembedaan dalam praktiknya. Menurut Surya (2016:203) Bimbingan dan konseling dilaksanakan dengan landasan semangat bhinneka tunggal ika, yaitu kesamaan di atas keragaman. Layanan bimbingan dan konseling hendaknya lebih berpangkal pada nilai-nilai budaya bangsa yang secara nyata mampu mewujudkan kehidupan yang harmoni dalam kondisi pluralistik.

Berdasarkan data dari catatan kasus bimbingan konseling SMP Negeri 1 Madiun, ditemukan munculnya masalah yang ada dalam lingkup sosialisasi peserta didik dengan latar belakang perbedaan suku. dan harus segera ditemukan solusi untuk mengatasi. Untuk itu, gagasan tentang konseling lintas budaya menjadi terobosan dan alternatif yang dapat digunakan oleh para pelaku bimbingan dan konseling. Pendidik Bimbingan Konseling dan agen Konseling lintas budaya yang berasal dari peserta didik mampu memberikan solusi pemecahan masalah para kliennya (peserta didik) yang memiliki latar belakang budaya berbeda-beda, baik dalam aspek bahasa, suku, etnis, maupun sistem keyakinan.

Sekolah adalah rumah kedua bagi peserta didik, dimana terdapat masyarakat kecil dengan berbagai macam keanekaragaman kultur, adat, sifat maupun kebiasaan. Sehingga dibutuhkan sikap komunikatif. Permasalahan tentang penyesuaian diri, dialami oleh peserta didik di SMP Negeri 1 Kota Madiun. Sehingga perlu dikaji dan perlu solusi alternatif. Maka, diperlukan proses penguatan sikap komunikatif "SI BANG KOIN DAYA" (Sikap Kebangsaan dengan Konseling Lintas Budaya) untuk penguatan pendidikan karakter menuju generasi unggul.

\section{Permasalahan}

Berdasarkan latar belakang masalah diatas, permasalahan yang perlu diatasi dapat dirumuskan sebagai berikut :

1. Bagaimana menumbuhkan sikap komunikatif "SI BANG KOIN DAYA" (Sikap Kebangsaan dengan
Konseling Lintas Budaya) untuk penguatan pendidikan karakter menuju generasi unggul ?

2. Bagaimana dampak dan hasil dari pelaksanaan sikap komunikatif peserta didik "SI BANG KOIN DAYA" (Sikap Kebangsaan dengan Konseling Lintas Budaya) untuk penguatan pendidikan karakter menuju generasi unggul ?

\section{Tujuan}

Berdasarkan permasalahan yang ada, tujuan dari makalah ini adalah : Mendeskripsikan langkah-langkah pelaksanaan kegiatan sikap komunikatif "SI BANG KOIN DAYA" (Sikap Kebangsaan Dengan Konseling Lintas Budaya) untuk penguatan pendidikan karakter menuju generasi unggul. Mengetahui hasil dan dampak pelaksanaan kegiatan sikap komunikatif "SI BANG KOIN DAYA" (Sikap Kebangsaan dengan Konseling Lintas Budaya) untuk penguatan pendidikan karakter menuju generasi unggul

\section{Manfaat}

Secara praktis mafaat dari makalah best practice ini adalah : Diperoleh strategi dalam pelaksanaan kegiatan sikap komunikatif komunikatif "SI BANG KOIN DAYA" (Sikap Kebangsaan dengan Konseling Lintas Budaya) untuk penguatan pendidikan karakter menuju generasi unggul. Ditemukanya langkah alternatif penyelesaian masalah penyesuaia diri pada peserta didik dengan pelaksanaan kegiatan sikap komunikatif "SI BANG KOIN DAYA" (Sikap Kebangsaan dengan Konseling Lintas Budaya) untuk penguatan pendidikan karakter menuju generasi unggul. Bagi warga sekolah dapat mengalami perubahan sikap serta terbentuknya karakter sikap komunikatif serta peduli sosial yang dapat diterapkan di lingkungan sekolah

\section{METODE}

Metode penyelesaian untuk mengatasi masalah penyesuaian diri serta hambatan penyesuaian diri yang dialami oleh peserta didik di SMP Negeri 1 Madiun, adalah dengan pemberdayaan melalui kegiatan konseling lintas budaya untuk menumbuhkan sikap komunikatif peserta didik dalam "SI BANG KOIN DAYA" (Sikap Kebangsaan dengan Konseling Lintas Budaya) untuk penguatan pendidikan karakter menuju generasi unggul. Hal ini sebagai upaya penguatan dalam implementasi pendidikan karakter.

Ada 18 karakter yang merupakan hal yang harus dimilikioleh setiap peserta didik. Adapun pemerintah melalui sekolah perlu mengoptimalkan pada kemampuan setiap peserta didik. Salah satu karakter terpenting yang perlu untuk dikembangkan oleh guru maupun orang tua adalah karakter sikap kebangsaan. Menurut Retno Listyarti (2017:37) sikap kebangsaan adalah rasa mencintai dan 
menjaga rasa persatuan dan kesatuan antar setiap generasi muda Indonesia.

Konseling lintas budaya dipandang penting karena sebagian besar peserta didik lebih sering membicarakan masalah-masalah yang terjadi disekolah menyangkut keseharian. Komposisi peserta didik di SMP Negeri 1 Madiun dengan latar belakang kebudayaan yang berbeda (Tionghwa dan Jawa) tidak jarang mengakibatkan terjadinya "konflik" di antara keduanya (Tionghwa dan Jawa), baik konflik secara langsung (fisik) maupun secara tidak langsung (psikis). Konflik secara fisik seperti terjadinya perkelahian, baik yang dilakukan antara satu individu dengan individu lainnya, dan tidak jarang juga konflik secara berkelompok (kelompok yang mewakili kesukuan ataupun ras). Walau Konflik secara fisik lebih sedikit dibandingkan konflik non fisik seperti pendiskreditan satu kelompok (Tionghwa dan Ambon) oleh kelompok (Jawa) lainnya di dalam satu kelas. Misalnya, ketika dalam satu kelas jumlah peserta didik jawa mayoritas (mendominasi) sering terjadi pendiskreditan kepada peserta didik yang berasal dari luar Jawa yang berjumlah minoritas.

Maka diperlukan Agen konseling lintas budaya yang berasal dari peserta didik. Hal tersebut terjadi karena remaja memiliki ketertarikan dan komitmen serta ikatan terhadap teman sebaya yang sangat kuat. Remaja merasa bahwa orang dewasa tidak dapat memahami mereka dan mereka yakin bahwa hanya sesama merekalah remaja dapat saling memahami. Keadaan yang demikian sering menjadikan remaja sebagai suatu kelompok yang eksklusif. Keeratan, keterbukaan dan perasaan senasib di antara sesama remaja dapat menjadi peluang bagi upaya memfasilitasi perkembangan peserta didik yang mengalami masalah dalam penyesuaian diri terutama yang berasal dari masalah budaya.

Maka proses menumbuhkan sikap komunikatif peserta didik komunikatif "SI BANG KOIN DAYA" (Sikap Kebangsaan dengan Konseling Lintas Budaya) untuk penguatan pendidikan karakter menuju generasi unggul, dilaksanakan dengan langkah langkah berikut :

a. Melakukan studi pendahuluan yang dimulai dengan analisis secara teoritik dan empirik terhadap problem dialami oleh peserta didik terutama tentang masalah penyesuaian diri, serta pendataan peserta didik yang mengalami masalah dalam penyesuaian diri yang bersumber dari permasalahan perbedaan budaya.

b. Penyeleksian agen konseling lintas budaya. Agen konseling lintas budaya diperoleh dari kegiatan pengalian potensi peserta didik diseluruh jenjang kelas dalam pemahaman kegiatan konseling dengan menekankan pada kemampuan personal peserta didik.

c. Pelaksanaan dan pemberdayaan kegiatan sikap komunikatif peserta didik dalam "SI BANG KOIN
DAYA" (Sikap Kebangsaan dengan Konseling Lintas Budaya) untuk penguatan pendidikan karakter menuju generasi unggul.

\section{KAJIAN TEORI}

Kehidupan manusia dalam era moderen berjalan tanpa sekat masa dan ruang. Setiap individu melewati kehidupan berbeda pada setiap pergantian waktu dan tempat. Salah satu peristiwa yang mewarnai kehidupan adalah proses interaksi, baik interaksi antar individu maupun interaksi antar masyarakat sosial. Komunikasi adalah seluruh rangkaian interaksi antar manusia, interaksi tersebut tidak mungkin terjadi tanpa komunikasi, baik secara individu maupun secara kolektif. Dalam proses pendidikan karakter mulai dioptimalkan peranan pendidik dalam membangun pendidikan karakter. Pendidikan karakter tidak hanya berfungsi sebagai penempatan diri dalam interaksi, berkolaborasi dengan peserta didik, namun juga diharapkan mampu menciptakan kultur berkarakter dilingkup sekolah. Zubaedi (2011:75) menyatakan bahwa "Komunikatif merupakan tindakan yang memperlihatkan rasa senang berbicara, bergaul, dan bekerjasama dengan orang lain.

Komunikatif merupakan kemampuan mempergunakan bahasa yang secara sosial dapat diterima dan memadai. Dengan kata lain, bahwa sikap komunikatif merupakan keadaan saling dapat berhubungan atau mudah di pahami. Dari uraian tersebut dapat ditarik kesimpulan bahwa sikap komunikatif merupakan bentuk kemampuan seseorang untuk mampu berinteraksi dengan baik dilingkungannya sehingga mudah diterima keberadaanya. Dalam makalah ini sikap komunikatif dibangun melalui "SI BANG KOIN DAYA" (Sikap Kebangsaan dengan Konseling Lintas Budaya) untuk penguatan pendidikan karakter menuju generasi unggul.

\section{HASIL DAN PEMBAHASAN}

Dalam pelaksanaan "SI BANG KOIN DAYA" (Sikap Kebangsaan dengan Konseling Lintas Budaya). Dimana peserta didik mampu berpartisipasi dalam kegiatan peduli sosial untuk menyelesaikan masalah yang ada dilingkup sekolah. Kehadiran "konselor" sebaya tidak menggantikan peran dan fungsi pendidik BK selaku konselor ahli. Dalam konseling teman sebaya, "konselor" sebaya adalah dipilih karena kemampuan, kelebihan serta kedekatan dengan peserta didik yang lainya. Dengan kata lain, "konselor" teman sebaya adalah jembatan penghubung (bridge) antara konselor dengan peserta didik (konseli) yang mengalami masalah dalam penyesuaian diri disekolah. Peserta didik yang mengalami masalah dalam penyesuaian diri cukup terbantu dengan adanya kegiatan konseling sebaya ini. Hal ini merupakan sebuah solusi alternatif dimana sekolah 
berperan serta dalam mengoptimalkan kemampuan seluruh peserta didik sebagai upaya penguatan pendidikan karakter.

\section{Gambar}

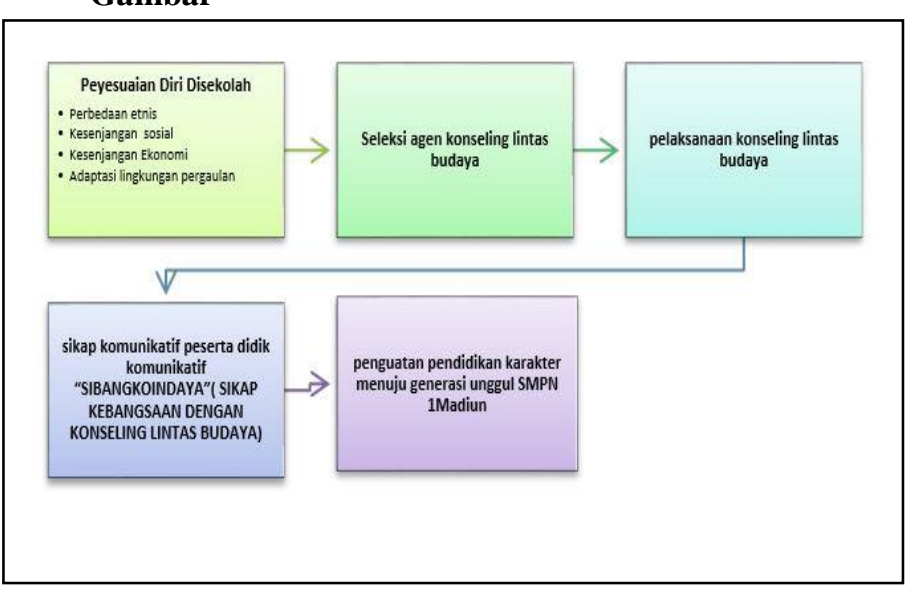

Gambar 1. Kerangka Berfikir

\section{PENUTUP}

\section{Simpulan}

Berdasarkan paparan dari pelaksanaan serta hasil kegiatan sikap komunikatif peserta didik dalam "SI BANG KOIN DAYA" (Sikap Kebangsaan dengan Konseling Lintas Budaya) sebagai upaya penguatan pendidikan karakter, dapat disimpulkan bahwa: Kegiatan konseling lintas budaya yang dilakukan oleh konselor sebayaa sebaya dengan pelaksanaan sikap komunikatif serta kepedulian sosial kepada peserta didik yang mengalami hambatan dalam penyesuaian diri merupakan penerapan kegiatan nyata yang dilakukan oleh SMP Negeri 1 kota Madiun, dalam penanaman nilai nilai karakter bangsa. Memberikan kesempatan peserta didik dalam menumbuhkan sikap toleransi. Yaitu sikap dan tindakan yang menghargai perbedaan agama, suku, etnis, pendapat, sikap, dan tindakan orang lain yang berbeda dari dirinya. Kegiatan sikap komunikatif peserta didik dalam "SI BANG KOIN DAYA" (Sikap Kebangsaan dengan Konseling Lintas Budaya) sebagai upaya penguatan pendidikan karakter mampu memupuk sikap dan tindakan yang selalu ingin memberi bantuan pada orang yang membutuhkan.

\section{Saran}

Dari hasil pembahasan serta kesimpulan kegiatan sikap komunikatif peserta didik dalam "SI BANG KOIN DAYA" (Sikap Kebangsaan dengan Konseling Lintas Budaya) sebagai upaya penguatan pendidikan karakter rekomendasi yang dapat disampaikan sebagai berikut:

a. Permasalahan yang dihadapi peserta didik yang dapat menghambat kegiatan proses belajar disekolah dapat diselesaikan apabila dilakukan dengan komitmen yang tinggi dari seluruh stakeholder.

b. Pelaksanaan kegiatan yang dilakukan oleh konselor dapat dioptimalkan sebagai wujud dari pelaksanaan sikap serta nilai dari pendidikan karakter.

c. Diperlukan konsistensi dalam pelaksanaan kegiatan sikap komunikatif peserta didik dalam "SI BANG KOIN DAYA” (Sikap Kebangsaan dengan Konseling Lintas Budaya) sebagai upaya penguatan pendidikan karakter

d. Diperlukan komitmen sebagai upaya penguatan pendidikan karakter di lingkungan sekolah

\section{DAFTAR PUSTAKA}

Alwi, Hasan. 2015. KBBI. edisi keempat. Jakarta: Balai Pustaka

Kurniawan, S. 2013. Pendidikan Karakter: Konsepsi \& Implementasinya secara Terpadu di Lingkungan Keluarga,Sekolah, Perguruan Tinggi, \&Masyarakat. Yogyakarta: Ar-Ruzz Media.

Listyarti Retno. 2017. Pendidikan Karakter dalam metode Aktif,Inovatif dan Kreatif. Jakarta: Esensi.

Moh surya, 2016. Psikologi Pembelajaran dan Pengajaran, Yogyakarta: Pustaka

Bani Quraisy.

Munandir. 2010. Ensiklopedia Pendidikan. Malang: UM Press

Sulistyarini. 2014. Psikologi Pendidikan dengan Pendekatan Baru. Bandung: Remaja Rosdakarya.

Suwarjo. 2008. Pedoman Konseling Teman Sebaya Untuk Pengembangan Resiliensi.Makalah disajikan Seminar Pengembangan Ilmu Pendidikan Fakultas Ilmu Pendidikan Universitas Negeri Yogyakarta

Zubaedi. 2012. Desain Pendidikan Karakter. Jakarta: Kencana 